\title{
Urea-Denaturation of Myosin B Prepared from Smooth Dogfish Muscle
}

\author{
Yoshio Kaminishi, ${ }^{*}$ Hidemasa Miki, ${ }^{*}$ and Jun-ichi Nishimoto* \\ (Received October 11, 1991)
}

\begin{abstract}
To study the effects of urea on the denaturation of myosin B prepared from smooth dogfish, myosin $\mathrm{B}$ was kept at $20^{\circ} \mathrm{C}$ for $10 \mathrm{~min}$ with various concentrations $(0-3.0 \mathrm{M})$ of urea, and the reduced viscosity was measured as a parameter for structural changes in myosin $B$. The decrease in the reduced viscosity of myosin B containing urea above $1.0 \mathrm{M}$ was similar to that of myosin in the presence of urea. However, the reduced viscosity of F-actin was slightly affected by urea even above $1.0 \mathrm{M}$.

The reduced viscosity of myosin B did not recovered to its initial level through the removal of urea at concentrations above $1.0 \mathrm{M}$ urea, but that of myosin recovered perfectly through the removal of urea at concentrations up to $3.0 \mathrm{~m}$ urea. In the presence of urea above $1.0 \mathrm{M}$, myosin $\mathrm{B}$ irreversibly dissociated into myosin and actin. Therefore, it is concluded that the urea denaturation of myosin B would be attributed to its dissociation into myosin and actin as well as the conformational changes of myosin molecules in the presence of urea above $1.0 \mathrm{M}$. Accordingly, shark myosin $\mathrm{B}$ is fairly stable under physiological concentrations of urea below $1.0 \mathrm{M}$.
\end{abstract}

The muscle of shark contains urea over a range of $250-350 \mathrm{~mm}^{1)}$ but myofibrillar proteins prepared from shark muscle are stable over a fairly wide range. It is well hnown that the hydrophobic group and the hydrogen bond of protein are severed in the presence of urea. ${ }^{2}$ As to the urea-resistibility of proteins prepared from shark muscle, Arai et al., ${ }^{3}$ Nishimoto et al., ${ }^{1)}$ Nishimoto, ${ }^{4)}$ and Kanoh et al. ${ }^{5}$ have reported that ATPase of myosin B or myofibrils of shark muscle were more urea-resistible than those from teleosts. However, overall changes in the structure of myosin B or myofibrils are unknown in the presence of urea. In a previous paper, ${ }^{\theta)}$ we described that structural changes in myosin B were indicated at a low temperature in the presence of urea when the effects of urea concentration were investigated on the thermal denaturation of shark myosin B. These results would be related to urea-denaturation of myosin $\mathrm{B}$ before heating.

The present study was designed to investigate the effects of urea on the denaturation of myosin B prepared from shark muscle by biochemical analysis, and to speculate the state of denaturation of shark myosin B in the presence of urea.

\section{Material and Methods}

\section{Material}

Sample specimens of smooth dogfish Mustelus manazo were purchased from the fish market of Ichihi in Kagoshima. The fish were frozen before rigor mortis and kept "at $-25^{\circ} \mathrm{C}$ until use.

\section{Preparation of Proteins}

Myosin B was prepared from the ordinary muscle by the method of Takashi et al. ${ }^{\text {r) }}$

Crude myosin was extracted by the method of Takashi et al. ${ }^{8)}$ For the purpose of purification, ${ }^{2)}$ the extract was added into a final concentration of $5 \mathrm{~mm} \mathrm{ATP}$ and $5 \mathrm{~mm} \mathrm{MgCl}_{2}$, and the mixture was immediately centrifuged at $200,000 \times$ $\mathrm{g}$ for $3 \mathrm{~h}$. The supernatant was diluted with 10 vol. of water and the precipitate was collected by centrifugation at $4,500 \times \mathrm{g}$ for $15 \mathrm{~min}$.

The crude actin was prepared by the method of Kitao et al..$^{10)}$ and the purification of F-actin was carried out by the method of Spudich and Watt. ${ }^{11}$ ?

Each protein was dissolved with a $0.45 \mathrm{M}$ $\mathrm{KCl}$-phosphate buffer (pH 6.8, ionic strength $0.5)$. Protein concentration was determined by the biuret method. ${ }^{12)}$

* Laboratory of Food Preservation, Faculty of Fisheries, Kagoshima University, Shimoarata, Kagoshima,

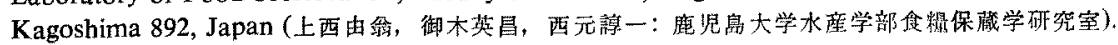




\section{Urea Treatment of Proteins}

Myosin B, myosin, and F-actin were treated in the solution containing $0.45 \mathrm{M} \mathrm{KCl}$-phosphate buffer ( $\mathrm{pH}$ 6.8) with various concentrations of urea $(0-3.0 \mathrm{M})$. After the proteins without urea had been preincubated at $20^{\circ} \mathrm{C}$ for $10 \mathrm{~min}$, the treatment of urea was carried out at $20^{\circ} \mathrm{C}$ for $10 \mathrm{~min}$ according to the results of the previous paper. ${ }^{8)}$ Experimental conditions for the renaturation of proteins were those in which urea was removed from myosin $\mathbf{B}$ and myosin by dalysis after the treatment with urea at $20^{\circ} \mathrm{C}$ for $10 \mathrm{~min}$. The dialysis was performed at $4^{\circ} \mathrm{C}$ overnight against $0.45 \mathrm{M} \mathrm{KCl}$-phosphate buffer (pH 6.8).

\section{Measurement of Reduced Viscosity}

The viscosity of proteins was measured at $20^{\circ} \mathrm{C}$ using an Ostwald-type viscometer No. 2 (Shibata Co. Ltd.). For proteins from which urea had been removed, the viscosity was measured after being kept at $20^{\circ} \mathrm{C}$ for $10 \mathrm{~min}$. The measurement of ATP sensitivity of myosin B was carried out by adding a final concentration of $5 \mathrm{~mm}$ ATP and $5 \mathrm{mM} \mathrm{MgCl}_{2}$.

\section{Results and Discussion}

Effects of Urea on the Structure of Myosin B The effect of urea on the viscosity of myosin $\mathrm{B}$ solution was investigated as compared with that of myosin and F-actin in the presence of urea. As shown in Fig. 1 (a), the reduced viscosity of myosin B decreased gradually as the concentration of urea increased to $0.7 \mathrm{M}$, then decreased sharply until $1.5 \mathrm{M}$. In the case of myosin, the reduced viscosity decreased gradually until $1.0 \mathrm{M}$, and then decreased sharply (Fig. 1 (b)). The curve of the reduced viscosity of myosin was similar to that of myosin B. In the case of F-actin, the reduced viscosity decreased gradually as the concentration of urea increased to $2.0 \mathrm{M}$ (Fig. 1 (c)). The behavior of F-actin was different from that of myosin $\mathrm{B}$ and myosin. Therefore, it was suggested that the fall in viscosity of myosin B was mainly dependent on urea-denaturation of myosin in the presence of urea above $1.0 \mathrm{M}$.

\section{Renaturation of Myosin $B$ after the Treatment of Urea}

The renaturation of myosin $B$ after the treatment of urea was examined by the measurement

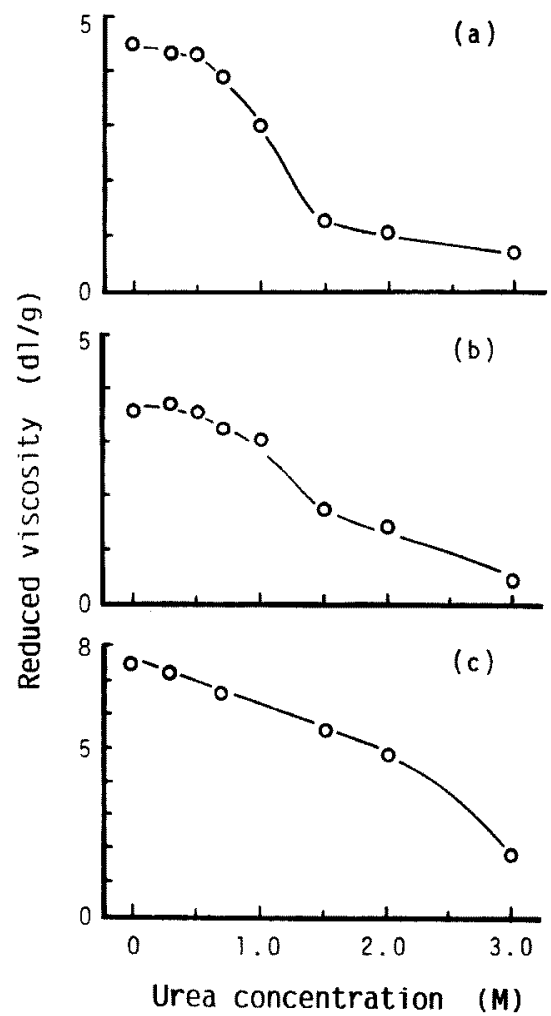

Fig. 1. The effect of urea concentration on the reduced viscosity of proteins.

Protein concentration was adjusted to $1.0 \mathrm{mg}$ / $\mathrm{m} l$ for myosin B (a) and myosin (b) and $0.4 \mathrm{mg}$ / for F-actin (c), respectively. Reduced viscosity was calculated from the equation, $\eta_{\mathrm{red}}=\left(\eta_{\mathrm{r}}-1\right)$ / $C$, where $\eta_{\mathrm{r}}$ is the relative viscosity and $C$ the protein concentration $(\%)$.

of the viscosity, and the viscosity of myosin B after the removal of urea was compared with that of myosin $B$ in the presence of urea. As shown in (a) and (b) of Fig. 2, the reduced viscosity of myosin $B$ recovered to its initial level below $1.0 \mathrm{M}$ urea, and that of myosin recovered completely up to $3.0 \mathrm{M}$ urea. For myosin $\mathrm{B}$ after the removal of urea above $1.0 \mathrm{M}$, the reduced viscosity recovered partially judging in terms of the difference in values of the reduced viscosity between Fig. 1 (a) and Fig. 2 (a). It was considered that the partial recovery phenomenon of myosin $B$ was due to myosin since the denaturation of myosin within myosin $\mathbf{B}$ was reversible by the removal of urea. In addition, the decrease of the viscosity for myosin in the presence of urea suggested conformational changes rather than denaturation. 


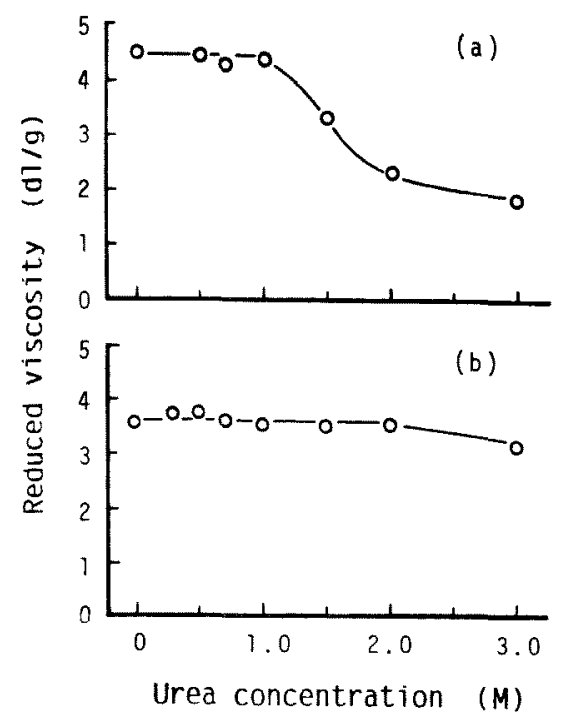

Fig. 2. Changes in the reduced viscosity of proteins from which urea was removed by dialysis after urea treatment.

Protein concentration was adjusted to $1.0 \mathrm{mg} /$ $\mathrm{m} /$ for myosin $\mathbf{B}(\mathrm{a})$ and myosin (b).

\section{Effects of Urea on the Dissociation of Myosin B}

ATP sensitivity of myosin B was investigated to clarify the behavior of myosin $B$ in the presence of urea above $1.0 \mathrm{M}$. As show in Fig. 3 (a), ATP sensitivity decreased sharply from 1.0 to $2.0 \mathrm{M}$ urea. These results indicated that myosin $B$ had dissociated into myosin and actin. The reduced viscosity of myosin $B$ by the addition of ATP decreased gradually above $1.0 \mathrm{M}$ urea, and the gradual decrease was regarded as the decrease of the reduced viscosity of myosin in the presence of urea. It was considered that the decrease of the reduced viscosity of myosin B as shown in Fig. 1 (a) was caused by the dissociation of myosin $\mathbf{B}$ into myosin and actin as well as conformational changes of myosin in the presence of urea. In the case of myosin B from which urea had been removed, ATP sensitivity remained unchanged at a high value up to $1.0 \mathrm{M}$ urea, and then decreased sharply until $2.0 \mathrm{M}$ urea (Fig. 3 (b)). The reduced viscosity of myosin B after the addition of ATP was more or less constant. Therefore, the dissociation of myosin B was irreversible in the presence of urea above $1.0 \mathrm{M}$. Also, the partial irreversibility of the reduced viscosity of myosin $\mathbf{B}$ shown in Fig. 2 (a) was dependent upon the dissociation into myosin and actin.

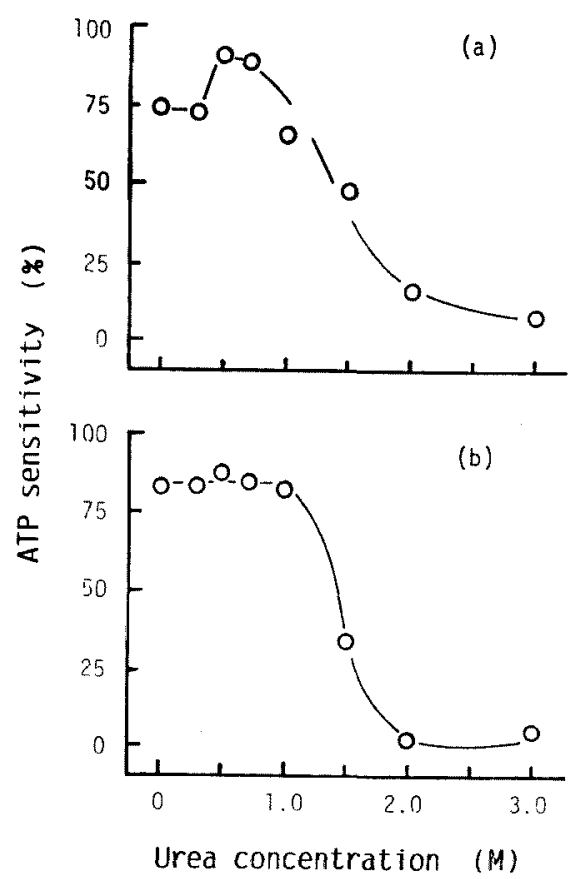

Fig. 3. Changes in ATP sensitivity of myosin B solution in the presence of urea (a) and after the removal of urea by dialysis (b).

ATP sensitivity was obtained from the equation, ATP sensitivity $=\left(\left(\log \eta_{\mathrm{r}}-\log \eta_{\mathrm{r}} \cdot\right.\right.$ ATP $)$, where $\eta_{\mathrm{r}}$ and $\eta_{\mathrm{r}}$ ATP are the relative viscosity of myosin $\mathrm{B}$ before and after the addition of $5 \mathrm{mM} \mathrm{ATP}-\mathrm{MgCl}_{2}$.

When myosin $\mathrm{B}$ was kept at $20^{\circ} \mathrm{C}$ for $10 \mathrm{~min}$, the stability of myosin $\mathbf{B}$ was lost in the presence of urea above $1.0 \mathrm{M}$, as mentioned above. In other words, this indicated that myosin B perpared from smooth dogfish muscle was fairly stable in the presence of urea below $1.0 \mathrm{M}$. As to the conformational changes of myosin in the presence of urea, it was presumed that the rod portion of the myosin molecule had been disrupted, because this portion is mainly formed by an $\alpha$-helical structure with many hydrogen bonds. The order of occurrence of the dissociation of myosin $B$ and the conformational changes of myosin could not be explained in this experiment. This explanation should be attempted in future.

\section{References}

1) J. Nishimoto and H. Miki: Studies on utilization and processing of muscle of unexploited elasmobranches-I. Heatinduced gelation of comminuted muscle of elasmobranches. Mem. Fac. Fish, Kagoshino Univ, 29, 1-19 (1980). 
2) J. Nakazawa, M. Nakazawa, and O. Hayaishi: Proteinprotein interaction, in "Chemistry of proteins" (ed. by $\mathbf{H}$. Ando, T. Imahori, T. Isemura, and Ohayaishi), vol, 3, Kyoritsu Shuppan, Tokyo, pp. 672-674 (1973).

3) K. Arai, A. Hasnain, and Y. Takano: Species specificity of muscle proteins of fishes against thermal and urea denaturation. Nippon Suisan Gakkaishi, 42, 687-695 (1976).

4) J. Nishimoto: Effect of urea on the $\mathbf{M g}^{2+-A T P a s e}$ activity of myofibrils prepared from marine elasmobranch muscles. Nippon Suisan Gakkaishi, 47, 1391 (1981).

5) S. Kanoh, S. Watabe, T. Takewa, and K. Hashimoto: Urearesistibility of myofibrillar proteins from the requiem shark. Nippon Suisan Gakkatshi, 51, 1713-1716 (1985).

6) Y. Kaminishi, H. Miki, and J. Nishimoto: Thermal denaturation of myosin $\mathbf{B}$ in the presence of urea. Ment. Fac. Fish. Kagoshima univ., 40, 103-109 (1991).

7) R. Takashi, K. Arai, and T. Saito: Studies on muscular proteins of fish-II. Preparation of actomyosin from carp muscle. Nippon Suisan Gakkaishi, 36, 168-172 (1970).

8) R. Takashi, K. Arai, and T. Saito: Studies on muscular proteins of Fish-I. Preparation of myosin from carp muscle. Nippon Suisan Gakkaishi, 36, 165-168 (1970).

9) K. Yagi: Myosin, in "Kinniku (muscle)" (ed. by S. Ebashi and K. Maruyama), Tokyo Kagaku Dojin, Tokyo, 1975, pp. 46.

10) M. Kitao, N. Seki, and K. Arai: Extraction and polymerizing ability of crude G-actin from fish muscle. Nippon Suisan Gakkaishi, 39, 1263-1269 (1973).

11) J. A. Spudich and S. Watt: The regulation of rabbit skeletal muscle contraction. J. Biol. Chem., 246, 4866-4871 (1971),

12) A. G. Gornall, C. J. Bardawill, and M. M. David: Determination of serum proteins by means of the biuret reaction, J. Biol. Chem., 177, 751-766 (1949). 